TAHKIM, Jurnal Peradaban dan Hukum Islam. Vol.3 No.l (Maret, 2020) | ISSN : 2597-7962

\title{
TINJAUAN TAFSIR AHKAM TENTANG PARIWISATA SYARIAH
}

\author{
Lina Pusvisasari \\ Dosen Sekolah Tinggi Agama Islam Al-Azhary Cianjur \\ nenglinapusvisa@gmail.com
}

\begin{abstract}
ABSTRAK
Dunia pariwisata saat ini sangat menyedihkan yang diakibatkan dari dampaknya yang negatif, seperti pergaulan bebas, alkoholisme, perdagangan narkoba, dan sebagainya. Pengamat pariwisata terus melakukan terobosan, sehingga pengembangan pariwisata di indonesia dapat berdampak positif bagi kehidupan masyarakat. diantaranya yaitu mengembangakan jenis pariwisata halal atau pariwisata syariah. Tujuan penelitian ini memberikan ikhtisar tentang Al-Quran dan Sunnah tentang pariwisata berdasarkan prinsip syariah, baik yang terkait dengan rekomendasi, tujuan, etika, prinsif dasar Islam dan manajemen pariwisata Islam sehingga dimasa depan pariwisata syariah menjadi bagian proses pendidikan mental dan spiritual masyarakat muslim. Metode yang digunakan dalam penelitian ini adalah metode kualitatif normatif yaitu telaah untuk memecahkan suatu masalah yang pada dasarnya bertumpu pada penelaahan kritis dan mendalam terhadap bahan-bahan pustaka yang relevan Hasil penelitian ini juga diharapkan dapat memberikan kontribusi positif bagi pemerintah dalam hal ini Departemen Pariwisata dan Kebudayaan baik di tingkat kabupaten / kota, provinsi dan nasional dalam rangka mengembangkan pariwisata syariah di indonesia.
\end{abstract}

Kata Kunci: al-Quran, al-Sunnah, Pariwisata.

\begin{abstract}
The world of tourism today is very sad due to its negative impacts, such as promiscuity, alcoholism, drug trafficking, and so on. Tourism observers continue to make inroads, so that the development of tourism in Indonesia can have a positive impact on people's lives. including developing a type of halal tourism or sharia tourism. The purpose of this study provides an overview of the Al-Quran and Sunnah about tourism based on sharia principles, both related to recommendations, goals, ethics, basic principles of Islam and management of Islamic tourism so that in the future sharia tourism will become part of the mental and spiritual education process of the Muslim community. The method used in this study is a normative qualitative method which is a study to solve a problem that basically relies on critical and in-depth review of relevant library materials. The results of this study are also expected to make a positive contribution to the government in this case the Ministry of Tourism and Culture both at the district / city, provincial and national levels in order to develop sharia tourism in Indonesia.
\end{abstract}

Keywords: al-Quran, al-Sunnah, Tourism. 
TAHKIM, Jurnal Peradaban dan Hukum Islam. Vol.3 No.l (Maret, 2020) | ISSN : 2597-7962

\section{A. PENDAHULUAN}

Pariwisata dikenal dalam istilah bahasa arab dengan kata "al-Siyahah, al-Rihlah, dan al-Safar" atau dalam bahasa Inggris dengan istilah "tourism"2, secara defenisi berarti suatu aktivitas atau kegiatan perjalanan yang dilakukan oleh manusia baik secara perorangan maupun kelompok di dalam wilayah negara sendiri ataupun negara lain dengan menggunakan kemudahan jasa dan faktor penunjang lainnya yang diadakan oleh pihak pemerintah maupun masyarakat dalam rangka memenuhi keinginan wisatawan (pengunjung) dengan tujuan tertentu. Dari definisi tersebut terlihat penekanannya pada kata perjalanan atau wisata dalam bahasa sansekerta atau dalam bahasa inggris dikenal dengan travel dan safar dalam bahasa arab. Jika dikaji secara mendalam dari istilah itu sendiri, baik secara sadar maupun tidak semua makhluk yang berada di jagat raya ini tidak akan terlepas dari perjalanan, termasuk makhluk sekecil semut sekalipun, perbedaannya hanya dari motif perjalanan itu sendiri, jika semut melakukan perjalanan adalah hanya untuk mencari makan, sedangkan manusia biasanya memiliki berbagai macam motif perjalanan, ada yang motifnya untuk rekreasi (menikmati objek dan daya tarik wisata, baik wisata alam maupun budaya), olah raga, mengunjungi sanak saudara, untuk kesehatan, pendidikan dan sebagainya. Dalam perkembangan pariwisata selanjutnya bangsa yang dikenal pertama kali melakukan perjalanan dengan motif bersenang-senang adalah bangsa Romawi, pada waktu itu mereka melakukan beratus-ratus mil hanya dengan menunggang kuda untuk melihat peniggalan-peniggalan Mesir Kuno dan mencari sumber air panas untuk kesehatan.

Sejarah juga mencatat bahwa Marcopolo merupakan orang pertama yang menjadi pelancong, ia mengembara dari benua Eropa ke Dataran Tiongkok dan kembali lagi ke Venesia antara tahun 1269 - 1295 M. Pelancong lainnya adalah seorang pemuda muslim yang bernama Ibnu Batuta, beliau lahir di Tunja (Maroko) dan dikenal sebagai seorang musafir yang paling banyak melakukan perjalanan di abad-abad pertengahan.

\footnotetext{
${ }^{1}$ Rohi Baalbaki, Al Mawrid A Modren Arabic English Dictionary, (Beirut: Dar al Ilm Almalayin, 1995), hlm. 569.

${ }^{2}$ John M. Echols and Hassan Shadily, Kamus Indonesia Inggris, (Jakarta: PT. Gramedia, 2010), hlm. 156.
} 
TAHKIM, Jurnal Peradaban dan Hukum Islam. Vol.3 No.l (Maret, 2020) | ISSN : 2597-7962

Perjalanannya dari Afrika Utara, Syiria, Makkah, kemudian menyelidiki negaranegara Arab, Mesopotamia, dan Persia serta di lanjutkan ke India dan tinggal selama kurang lebih 8 tahun di istana Sultan Delhi kemudian di utus ke China sebagai Duta Besar. Dari semua pengalamannya dalam melakukan perjalanan tersebut dapat di tuangkan ke dalam sebuah buka yang berjudul " The First Traveller of Moslim” ( Orang Islam pertama yang melakukan perjalanan). Ibnu Batuta adalah seorang alim (cendekiawan) yang berasal dari negara Maroko yang pernah berkelana ke berbagai pelosok dunia pada abad pertengahan. ${ }^{3}$

\section{B. METODE PENELITIAN}

Metode yang digunakan dalam penelitian ini adalah metode kualitatif normatif yaitu telaah untuk memecahkan suatu masalah yang pada dasarnya bertumpu pada penelaahan kritis dan mendalam terhadap bahan-bahan pustaka yang relevan. Dengan kata lain metode penelitian kualitatif adalah penelitian yang mengungkap situasi sosial tertentu dengan mendeskripsikan kenyataan secara benar, dibentuk oleh kata-kata berdasarkan data yang relevan yang diperoleh dari situasi yang alamiah. ${ }^{4}$

\section{PEMBAHASAN}

\section{Pengertian Pariwisata dalam Al-Quran dan Sunnah}

Dalam Al-Qur'an maupun Sunnah Rasulullah Saw tidak ditemukan kata pariwisata secara harfiah, namun terdapat beberapa kata yang menunjuk kepada pengertian dengan lafad yang berbeda namun secara umum maknanya sama, setidaknya penulis temukan tujuh bentuk redaksi kalimat, diantaranya adalah :

a. "Sara-Yasiru-Siru-Sairan-Saiyaratan" : (berjalan, melakukan perjalanan), dari kata tersebut dijumpai kata "saiyar, muannatsnya saiyahrah" dengan makna yang banyak menempuh perjalanan, lebih dikenal dengan nama mobil. Kata-kata yang menunjukkan makna tersebut terdapat dalam Qs. al-An'am (6) : 11, Qs. Annamal

\footnotetext{
${ }^{3}$ Dunn, Ross E. The Adventures of Ibn Battuta, University of California Press, First published in 1986. (T.tp: 2005), hlm. 20. hlm. 25
} 
TAHKIM, Jurnal Peradaban dan Hukum Islam. Vol.3 No.l (Maret, 2020) | ISSN : 2597-7962

(27) : 69, Qs. al-Ankabut (29) : 20, Qs. al-Rum (30) : 42, Qs. Saba' (34) : 18 dan 28, Qs. al-Mukmin" (40) : 21, Qs. Fathir (35) : 35, dan Qs. al-Nahl (16) : $36^{5}$ Pada surat-surat di atas dijelaskan dengan beragam redaksi,anjuran melakukan perjalanan dengan menggunakan kata kerja sedang berlansung dan kata perintah, sehingga di dapat motivasi para Rasul dan Nabi terdahulu dalam melakukan perjalanan.

b. "Al-Safar" : (Perjalanan) terdapat dalam Qs. al- Baqarah (2) : 184,185,283, Qs. An-nisa'(4) : 43, Qs. al- Maidah (5) : $6 .{ }^{6}$ Dalam beberapa surat dan ayat di atas dijelaskan tentang keadaan orang yang sedang dalam musafir diberikan kemudahan dan keringanan dalam ibadah, seperti menjama' dan mengqasar sholat begitu juga di bolehkan berbuka bagi yang berpuasa.

c. "Rihlah" : (Perjalanan) terdapat dalam Qs. Qurays (106) : 1-4. ${ }^{7}$ menerangkan Kebiasaan suku Qiraisy melakukan perjalanan bisnis/berdagang pada musim dingin ke Yaman dan musim panas ke negeri Syam. Rasulullah Saw dalam hal ini menganjurkan ummatnya untuk melakukan perjalanan/wisata rohani ke tiga Masjid, sabagaimana dalam sabda Beliau :

"Tidaklah kamu di anjurkan melakukan perjalanan melainkan kepada tiga Masjid, al-Masjid al-Haram, Masjid al-Rasul, dan Masjid al-Aqsa". ${ }^{8}$

d. "Hajara-Yuhajiru-Muhajiran" : (Berhijrah, berpindah) terdapat dalam Qs. Annisa' (4) : 100. ${ }^{9}$ Menerangkan keadaan orang yang berhijrah karena Allah Swt dan Rasul-Nya maka orang tersebut mendapatkan pahala, walaupun akan banyak mendapatkan tantangan dan cobaan.

e. "Asra" : (memperjalankan) terdapat dalam Qs. al-Isra' (17) : 1. ${ }^{10}$ Kisah Isra' dan Mi’raj, misi perjalanan Rasulullah Saw dari Masjid Haram Makkah ke Masjid alAqsa di Palestina, lalu menaiki langit menjemput perintah sholat.

\footnotetext{
${ }^{5}$ Al-Raghib al-Alashfihani, Mu'jam al-Quran Li Alfaz al-Quran, (Beirut: Dar Fikr, 1989), hlm 105.

${ }^{6}$ Ibid . hlm. 112.

7 Ibid. hlm. 89. Lihat juga Muhammad Fuad Abdul Baqy, Mu'jam al-Mufahris Li-Alfaz alQuran, (Istanbul: Maktabah Islamiyah, 1984 ).

${ }^{8}$ Imam Bukhari. Shahih Bukhari...hlm. 491.

${ }^{9}$ Ibid. hlm. 74.

${ }^{10}$ Ibid. hlm. 23.
} 
TAHKIM, Jurnal Peradaban dan Hukum Islam. Vol.3 No.l (Maret, 2020) | ISSN : 2597-7962

f. "Saha-Yahsihu-Saihan-Siyahah-Sa ihun" : (Berjalan atau bepegian), tedapat dalam Qs. Al-Taubah (9) : 2 dan 112. ${ }^{11}$ Dalam dua ayat di atas dijelaskan tentang anjuran melakuan perjalanan di buka bumi dalam rangka melakukan ibadah dan anjuran melawat atau bertamasya ke suatu negeri untuk melihat pemandangan dan kagungan ciptaan Allah Swt. Bahkan Allah Swt memuji orang-orang yang melakukan perjalanan, wisatawan dan pelancong dengan istilah "Al-Saih" berbarengan dengan orang bertaubat, memuji Allah, orang yang ruku', orang yang sujud, berjihad, dan beramar ma'ruf dan nahi munkar. Senada dengan hal di atas Rasulullah Saw bersabda :

"Dari Sa'ad bin Mas'ud, bahwasanya 'Usman bin Maz'un datang menemui Nabi SAW, dia berkata: "Izinkanlah kami dikebiri!” Lalu Rasulullah SAW menjawab: "Sesungguhnya pengebirian umatku adalah dengan cara berpuasa." Dia berkata lagi: "Ya Rasulullah! Izinkanlah kami hidup melakukan siyahah (pergi ke padang pasir jauh dari orang ramai, meninggalkan segala kesenangan dan perkaraperkara yang mubah serta mengekang hawa nafsu)." Lalu Rasul menjawab: "Siyahah umatku adalah dengan cara berjihad fi sabilillah." Dia berkata lagi: "Wahai Rasulullah, izinkanlah kami menjalani hidup seperti seorang rahib." Rasulullah menjawab: "Sesungguhnya kerahiban umatku adalah dengan cara duduk di masjid- masjid menunggu masuknya waktu sholat.",12

g. "Dharaba" : (melakukan perjalanan), terdapat dalam Qs. Annisa' (4) : 101. ${ }^{13}$ Pada ayat ini di jelaskan tentang kemudahan dan keringanan dengan mengqasar shalat bagi orang yang dalam perjalanan.

\section{Anjuran Al-Quran dan Sunnah untuk Berwisata}

Seruan Islam untuk melakukan perjalanan pariwisata lebih luas dari tujuan yang dewasa ini diungkapkan dalam masalah kepariwisataan. Dalam Islam kita mengenal istilah hijrah, haji, ziarah, perdagangan, dan mencari ilmu pengetahuan yang merupakan

\footnotetext{
${ }^{11}$ Ibid. hlm. 102.

${ }^{12}$ Ibid. hlm. 174.

13 Ibid. hlm. 174.
} 
TAHKIM, Jurnal Peradaban dan Hukum Islam. Vol.3 No.l (Naret, 2020) | ISSN : 2597-7962

diantara faktor yang dijadikan alasan Islam untuk mendorong umatnya melakukan perjalanan. Keberhasilan manusia dalam mencapai kemajuan di bidang ilmu, teknologi, komunikasi, dan transportasi, telah memberi kemudahan dalam melakukan perjalanan wisata.

Dengan demikian kebiasaan melakukan perjalanan wisata memiliki peran yang besar dalam kehidupan suatu komunitas bangsa. Hijrah merupakan perjalanan ibadah dan politis dalam Islam. Hijrah bisa berupa perjalanan dari satu kota ke kota lain, atau dari negara ke negara lain, atau dari dirinya sendiri untuk menuju Allah Swt untuk perubahan kearah kebaikan. Hijrah biasanya memiliki dua tujuan, yaitu menyebarkan agama Islam atau keluar dari komunitas yang tidak kondusif dan dari wilayah kekuasaan sebuah pemerintahan yang kejam .

Islam dengan konsep hijrahnya menyerukan kaum muslimin agar ketika kondisi hidupnya tidak memberi kesempatan baginya untuk berkembang dan maju, mereka harus berhijrah ke negeri lain dan membebaskan dirinya dari tekanan pemerintahan yang kejam. Hal ini ditegaskan dalam Qs. Annisa' (4) : $100 .{ }^{14}$ Demikian pula, haji dan ziarah merupakan bentuk perjalanan wisata dalam Islam yang penuh nilai-nilai maknawi.

Kaum muslimin pada waktu-waktu yang telah ditentukan melakukan perjalanan meninggalkan tanah air menuju tanah suci. Di sini, kaum muslimin dari berbagai penjuru dunia bertemu dan terjadilah komunikasi dan pengenalan terhadap berbagai budaya kaum muslimin di dunia. Seruan untuk melakukan perjalanan haji ini Allah firmankan dalam Qs. Ali Imran (3) : 97. Sementara itu, perjalanan wisata ziarah, dilakukan untuk mengunjungi berbagai tempat suci di dunia, seperti mengunjungi tiga masjid Masjid alHaram Makkah, Masjid Nabawi dan Masjid Al-Aqsa di Palestina, Ziarah ke Maqam Rasulullah dan para sahabat serta maqam Baqi' dan tempat-tempat bersejarah dibelahan dunia Islam lainnya. Wisata ziarah akan memberikan pengaruh besar dalam jiwa manusia. Manusia akan terkenang pada kehidupan Rasullah SAW dan keluarga suci beliau.

${ }^{14}$ Penjelasan lebih dalam tentang pinsif dan tujuan hijrah, dapat merujuk tafsir suat Annisa' : 100, dalam tafsir Abu Abdullah Muhammad Al-Anshari Al-Qurthubi, Al-Jami' Li Al-Ahkam al-Quran, (Beirut: Dar al-Kutub alIlmiah, 1993 , juz 3), hlm. 59, dan Ibnu Katsir, Imaduddin Abu al- Fida' Ismail, Tafsir alQuran al-Karim, (BeirutL: Dar Maktabah al-Hilal,1986 ), hlm. 94. 
TAHKIM, Jurnal Peradaban dan Hukum Islam. Vol.3 No.l (Maret, 2020) | ISSN : 2597-7962

Said Quthub berkomentar tentang anjuran dan hikmahwisata ziarah : "Dengan cara ini, mereka akan terdorong untuk meneladani kehidupan para manusia suci itu dan selalu berusaha untuk mencapai tingkat manusia yang sempurna atau insan kamil", ${ }^{15}$ sebagaimana firman Allah dalam Qs. Arrum (30) : 9. Lain lagi kebiasaan suku Quraisy, mereka terbiasa melakukan perjalanan bisnis ke berbagai negara pada musim dingin ke negeri Yaman dan musim panas ke negeri Syam sehingga Allah Swt mengabadikan mereka dalam satu surat yaitu Qs. Quraisy (106) : 1 - 4. Tauladan kita Rasulullah Saw juga melakukan perjalanan perdagangan ke negeri Syam begitu juga para Sahabat sebagian mereka telah melakukan rihlah tijariyah (perjalanan bisnis).

Begitu juga perhatian Rasulullah Saw terhadap para Sahabat dalam hal menambah wawasan keilmuan atau sebagai penyiar ilmu dan penyebar dakwah, mengutus para sahabat ke negeri-negeri sekitar jazirah arab dan benua lainnya. Seperti mengutus Muaz bin Jabal ke Yaman. Pada masa Khalifah Umar bin Khattab diutuslah Amru bin As untuk menyebarkan Islam di Mesir.

Dalam tradisi keilmuan para ahli hadis dikenal istilah al-Rihlah fi Thalib AlHadis, yaitu mereka yang melakukan perjalanan mencari hadis-hadis dari sumbernya, melacak kebenaran suatu hadis, meneliti keadaan Perawi dan melacak Ilalnya (cacat), bahkan mencari satu hadis saja mereka melakukan perjalanan ke berbagai negara dan memakan waktu yang lama. ${ }^{16}$ Seperti Muqshid Abi Ayub yang melakukan perjalanan dari Madinah al-Munawwarah menuju Mesir untuk memastikan sebuah hadis yang telah di dengarnya dari Rasulullah Saw ataukah ada sahabat lain yang mendengarnya.

Tradisi keilmuan dalam melakukan perjalanan ilmiah dikalangan ahli hadis adalah suatu kewajiban dalam rangka meneliti, melacak dan mendiskusikan suatu hadis, maka tidak jarang diantara mereka melakukan perjalanan dari suatu negera ke negera lain begitu juga perjalanan dari suatu daerah ke daerah lain dalam suatu negara.

15 Said Quthub, Fizhila Li al-Quran, (Cairo: Dar Syuruq, 2001 ), hlm.28.

${ }^{16}$ Istilah ini terdapat diberbagai kitab Musthalah Hadis, yang merupakan bagian dari pembahasan yang terdapat dalam disiplin ilmu ini. Lebih jelas bisa dilihat dalam Ibnu Shalah, Tahqiq Nuruddin 'Athar, Ulum al-Hadis, (Damaskus: Dar Fikr, 1998), hlm. 256. 
TAHKIM, Jurnal Peradaban dan Hukum Islam. Vol.3 No.l (Maret, 2020) | ISSN : 2597-7962

\section{Beberapa Tujuan Pariwisata Menurut Al-Quran dan Sunnah}

Dalam Al-Quran banyak dijelaskan tujuan berwisata, diantara tujuan-tujuan tersebut adalah :

\section{a. Mengenal Sang Pencipta dan Meningkatkan Nilai Spiritual}

Tujuan Islam dalam menggalakkan pariwisata, yang merupakan tujuan paling utama, adalah untuk mengenal Tuhan. Dalam berbagai ayat Al-Quran, Allah swt menyeru manusia untuk melakukan perjalanan di atas bumi dan memikirkan berbagai fenomena dan penciptaan alam. Dalam Qs. Allah berfirman Ankabut (29) : 20 ;

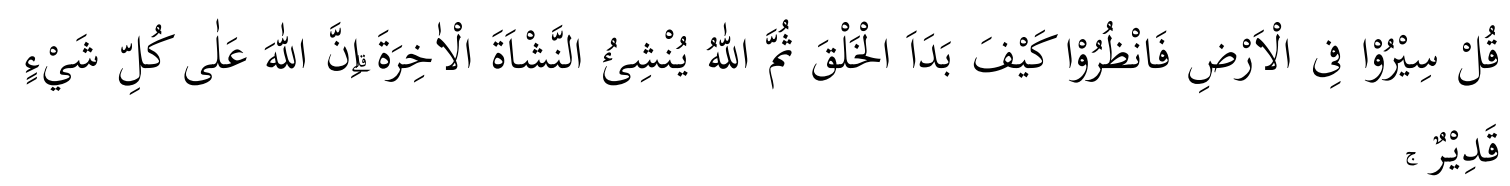

"Katakanlah, "Berjalanlah di bumi, maka perhatikanlah bagaimana (Allah) memulai penciptaan (makhluk), kemudian Allah menjadikan kejadian yang akhir. Sungguh, Allah Mahakuasa atas segala sesuatu." (QS. Al Ankabut : 20)

\section{b. Tafsir Surat Al Ankabut Ayat 20}

\section{1) Tafsir Jalalain}

(Katakanlah, "Berjalanlah kalian di muka bumi, maka perhatikanlah bagaimana Allah memulai penciptaan-Nya) yakni menciptakan orang-orang yang sebelum kalian, kemudian Dia mematikan mereka (lalu Allah menjadikannya sekali lagi) dapat dibaca An Nasy-atal akhirata dan An Nasy-atal ukhra. (Sesungguhnya Allah Maha Kuasa atas segala sesuatu) antara lain ialah memulai dan mengulanginya.

\section{2) Tafsir Ibnu Katsir}

\section{Surat Al Ankabut Ayat 19-20}

Tafsir Surat Al-'Ankabut: 19-23 Dan apakah mereka tidak memperhatikan bagaimana Allah menciptakan (manusia) dari permulaannya, kemudian mengulanginya (kembali). Sesungguhnya yang demikian itu adalah mudah bagi Allah. Katakanlah, ""Berjalanlah di (muka) bumi, maka perhatikanlah bagaimana Allah menciptakan (manusia) dari permulaannya, kemudian Allah menjadikannya sekali lagi. Sesungguhnya 
TAHKIM, Jurnal Peradaban dan Hukum Islam. Vol.3 No.l (Maret, 2020) | ISSN : 2597-7962

Allah Mahakuasa atas segala sesuatu. Allah mengazab siapa yang dikehendaki-Nya dan memberi rahmat kepada siapa yang dikehendaki-Nya, dan hanya kepada-Nyalah kamu akan dikembalikan. Dan kamu sekali-kali tidak dapat melepaskan diri (dari azab Allah) di bumi dan tidak (pula) di langit dan sekali-kali tiadalah bagimu pelindung dan penolong selain Allah.

Dan orang-orang yang kafir kepada ayat-ayat Allah dan pertemuan dengan Dia, mereka putus asa dari rahmat-Ku, dan mereka itu mendapat azab yang pedih. Allah Subhanahu wa ta'ala. berfirman, menceritakan kisah Nabi Ibrahim a. s. , bahwa Ibrahim memberi petunjuk kepada kaumnya untuk membuktikan adanya hari berbangkit yang mereka ingkari melalui apa yang mereka saksikan di dalam diri mereka sendiri. Yaitu bahwa Allah menciptakan mereka yang pada sebelumnya mereka bukanlah sebagai sesuatu yang disebut-sebut (yakni tiada). Kemudian mereka ada dan menjadi manusia yang dapat mendengar dan melihat. Maka Tuhan yang memulai penciptaan itu mampu mengembalikannya menjadi hidup kembali, dan sesungguhnya mengembalikan itu mudah dan ringan bagi-Nya.

Kemudian Ibrahim a. s. memberi mereka petunjuk akan hal tersebut melalui segala sesuatu yang mereka saksikan di cakrawala, berupa berbagai macam tanda-tanda kekuasaan Allah yang telah menciptakannya. Yaitu langit dan bintang-bintang yang ada padanya, baik yang bersinar maupun yang tetap dan yang beredar. Juga bumi serta lembah-lembah, gunung-gunung yang ada padanya, dan tanah datar yang terbuka dan hutan-hutan, serta pepohonan dan buah-buahan, sungai-sungai dan lautan; semuanya itu menunjukkan statusnya sebagai makhluk, juga menunjukkan adanya yang menciptakannya, yang mengadakan, serta memilih segalanya.

Dialah yang bila ingin menciptakan hanya mengatakan terhadap sesuatu, ""Jadilah, "" maka terjadilah ia. Karena itulah disebutkan oleh firman-Nya, menyitir katakata Nabi Ibrahim as.: Dan apakah mereka tidak memperhatikan bagaimana Allah menciptakan (manusia) dari permulaannya, kemudian mengulanginya (kembali). Sesungguhnya yang demikian itu adalah mudah bagi Allah. (Al-'Ankabut: 19) Sama dengan apa yang disebutkan oleh firman-Nya dalam ayat yang lain: Dan Dialah yang menciptakan (manusia) dari permulaan, kemudian mengembalikannya 
TAHKIM, Jurnal Peradaban dan Hukum Islam. Vol.3 No.l (Maret, 2020) | ISSN : 2597-7962

menghidupkannya) kembali, dan menghidupkan kembali itu adalah lebih mudah bagiNya. (Ar-Rum: 27) Adapun firman Allah Subhanahu wa ta'ala. : Katakanlah, "'Berjalanlah di (muka) bumi, maka perhatikanlah bagaimana Allah menciptakan (manusia) dari permulaannya, kemudian Allah menjadikannya sekali lagi. (Al-'Ankabut: 20) Yakni kelak di hari kiamat. Sesungguhnya Allah Mahakuasa atas segala sesuatu. (Al'Ankabut: 20) Kedudukan ini sama dengan apa yang disebutkan oleh Allah Subhanahu wa ta'ala. dalam ayat lain melalui firman-Nya: Kami akan memperlihatkan kepada mereka tanda-tanda (kekuasaan) Kami di segenap ufuk dan pada diri mereka sendiri sehingga jelaslah bagi mereka bahwa Al-Qur'an itu adalah benar. (Fussilat: 53) Dan firman Allah Subhanahu wa ta'ala. : Apakah mereka diciptakan tanpa sesuatu pun ataukah mereka yang menciptakan (diri mereka sendiri)' Ataukah mereka telah menciptakan langit dan bumi itu' Sebenarnya mereka tidak meyakini (apa yang mereka katakan). (At-Tur: 35-36) Adapun firman Allah Subhanahu wa ta'ala. : Allah mengazab siapa yang dikehendaki-Nya dan memberi rahmat kepada siapa yang dikehendaki-Nya.

Lebih jauh dari itu, bila kita memiliki tujuan yang maknawi, yaitu untuk mengenal berbagai ciptaan Allah Swt. Perjalanan wisata seperti ini bisa disebut sebagai wisata rohani, yang akan menerangi hati, membuka mata dan melepaskan jiwa dari belenggu tipu daya dunia. Penegassan hal ini diperkuat fiman Allah Swt dalam Qs. Ar-Rum (30) : ayat 9 ;

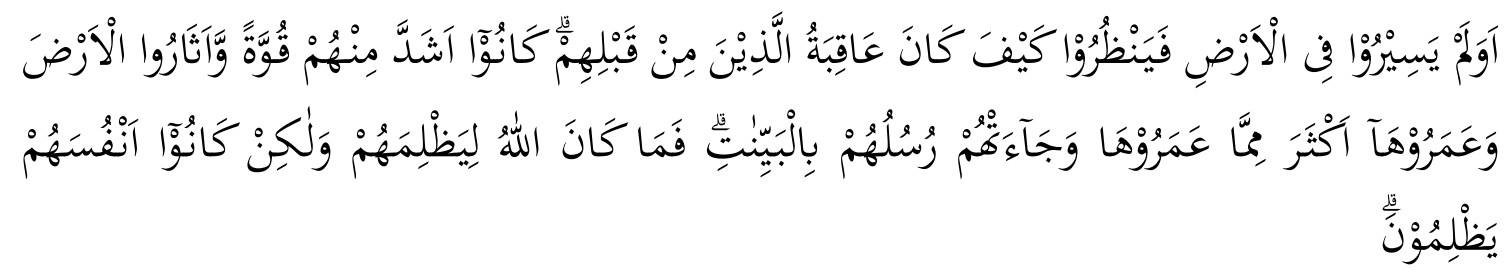

"Dan tidakkah mereka bepergian di bumi lalu melihat bagaimana kesudahan orangorang sebelum mereka (yang mendustakan rasul)? Orang-orang itu lebih kuat dari mereka (sendiri) dan mereka telah mengolah bumi (tanah) serta memakmurkannya melebihi apa yang telah mereka makmurkan. Dan telah datang kepada mereka rasulrasul mereka dengan membawa bukti-bukti yang jelas. Maka Allah sama sekali tidak berlaku zalim kepada mereka, tetapi merekalah yang berlaku zalim kepada diri mereka sendiri. (QS. Ar Rum : 9). 
TAHKIM, Jurnal Peradaban dan Hukum Islam. Vol.3 No.l (Maret, 2020) | ISSN : 2597-7962

\section{c. Tafsiir Surat Ar-rum Ayat 9}

\section{1) Tafsir Jalalain}

(Dan apakah mereka tidak mengadakan perjalanan di muka bumi dan memperhatikan bagaimana akibat orang-orang yang sebelum mereka') maksudnya umatumat sebelum mereka, mereka dibinasakan karena mendustakan rasul-rasulnya. (Orangorang itu adalah lebih kuat dari mereka sendiri) seperti kaum Ad dan kaum Tsamud (dan telah mengolah bumi) mereka telah mencangkul dan membajaknya untuk lahan pertanian dan perkebunan (serta memakmurkannya lebih banyak dari apa yang telah mereka makmurkan) artinya lebih banyak dari apa yang telah dimakmurkan oleh orang-orang kafir Mekah (dan telah datang kepada mereka rasul-rasul mereka dengan membawa bukti-bukti yang nyata) hujah-hujah yang jelas. (Maka Allah sekali-kali tidak berlaku lalim kepada mereka) dengan membinasakan mereka tanpa dosa (akan tetapi merekalah yang berlaku lalim kepada diri sendiri) karena mereka mendustakan rasul-rasul mereka.

\section{2) Tafsir Ibnu Katsir Ar- Rum Ayat 9}

Dan apakah mereka tidak mengadakan perjalanan di muka bumi. (Ar-Rum: 9) lalu menggunakan pemahaman dan akal serta penalaran mereka, juga menggunakan pendengaran mereka untuk mendengar kisah-kisah umat-umat terdahulu. dan memperhatikan bagaimana akibat (yang diderita) oleh orang-orang yang sebelum mereka' Orang-orang itu adalah lebih kuat daripada mereka (sendiri). (Ar-Rum: 9) Yakni umatumat terdahulu dan generasi-generasi yang silam lebih kuat daripada kalian, hai orangorang yang diutus kepada mereka Nabi Muhammad; bahkan umat-umat terdahulu itu jauh lebih banyak harta dan anak-anaknya daripada kalian.

Tiadalah yang diberikan kepada kalian berjumlah sepersepuluh dari apa yang diberikan kepada mereka. Mereka hidup di dunia dalam kondisi yang jauh lebih mapan daripada kalian; tingkat kehidupan kalian jauh di bawah mereka. Mereka sempat membangun dunia dengan bangunan-bangunan yang tinggi-tinggi dan meramaikan dunia lebih banyak daripada kalian, bahkan mereka mengolah dan menggarap tanah jauh lebih banyak daripada apa yang kalian garap. Hanya saja ketika datang kepada mereka rasulrasul mereka yang datang membawa bukti-bukti dari Allah, mereka berbangga diri 
TAHKIM, Jurnal Peradaban dan Hukum Islam. Vol.3 No.l (Maret, 2020) | ISSN : 2597-7962

dengan apa yang telah mereka capai dari kehidupan dunia. Maka Allah mengazab mereka disebabkan dosa-dosa mereka.

Akhirnya tiada seorang pun yang dapat melindungi mereka dari azab Allah. Harta benda dan anak-anak mereka sama sekali tidak dapat menyelamatkan mereka dari pembalasan Allah, tidak pula dapat membela mereka barang sedikit pun dari azab Allah. Allah sama sekali tidak bertujuan menganiaya mereka dengan menimpakan azab dan pembalasanNya atas mereka itu. akan tetapi merekalah yang berlaku zalim kepada diri sendiri. (Ar-Rum: 9) Maksudnya, tiada lain yang menimpa diri mereka hanyalah akibat dari perbuatan mereka sendiri, karena mereka mendustakan ayat-ayat Allah dan memperolok-olokkannya. Azab yang menimpa mereka itu tiada lain sebagai akibat dari dosa-dosa mereka sendiri yang mendustakan rasul-rasul Allah dan ayat-ayat-Nya.

\section{Berbisnis, Membuka Peluang Usaha Sebagai Salah Satu Pemberdayaan Potensi Daerah}

Tujuan lain pariwisata yang dianjurkan Islam adalah untuk berniaga atau berbisnis. Dewasa ini perdagangan juga menjadi salah satu tujuan terpenting dari pariwisata. Dalam Islam, mencari penghasilan melalui usaha yang benar dan halal merupakan salah satu hal yang sangat dianjurkan. Berbagai ayat dan riwayat Islam menunjukkan pujian kepada usaha perkonomian yang sehat, sebagaimana ibadah-ibadah lainnya. Tentang kebiasan masyarakat suku Quraisy melakukan perjalanan periagaan ke Yaman dan Syam, ${ }^{17}$ begitu juga penegasan Allah Swt dalam Qs. al-Jumuah (62) : 10 Imam Ibnu Katsir tentang ayat ini mengatakan "anjuran bertebaran di permukaan bumi untuk mencari rezki dengan cara yang halal dan baik setelah melaksanakan ibadah”. Imam Ali r.a berkata, "Berdaganglah agar Allah menurunkan berkahnya kepadamu."18 Pemberian motivasi seperti ini telah membuat kaum muslimin melakukan perjalanan ke berbagai penjuru dunia untuk berdagang mencari penghasilan, Yang menarik dari

${ }^{17}$ Penjelasan lebih lanjut bisa di lihat pada Quraisy Shihab,. Tafsir al-Misbah, (Jakarta: lentera hati, 2002 M), hlm. 537-538.

${ }^{18}$ Ibnu Katsir, Imaduddin Abu al-Fida' Ismail, Tafsir al-Quran al-Karim, (Beirut:Dar Maktabah al-Hilal, 1986 ), hlm. 554. 
TAHKIM, Jurnal Peradaban dan Hukum Islam. Vol.3 No.l (Maret, 2020) | ISSN : 2597-7962

fenomena ini adalah bahwa melalui kegiatan perjalanan dagang ini pula Islam tersebar ke berbagai penjuru dunia, termasuk ke Indonesia. Maka potensi-potensi daerah dalam menumbuhkan geliat usaha ekonomi masyarakat dikembangkan melalui program Pemerintah Daerah, dengan meningkatkan usaha kecil dan menengah serta membangun pusat-pusat industri yang layak dan cocok dengan pengembangan daerah.

\section{Menambah Wawasan Keilmuan}

Faktor ilmu dan wawasan juga merupakan faktor penting yang membuat pariwisata berkembang dalam budaya Islam. Sejak masa munculnya Islam, agama mulia ini telah memotivasi umatnya untuk menuntut ilmu, bahkan sampai ke negeri yang jauh. Salah satu sebab penting dari tumbuh dan berkembangnya peradaban Islam adalah perjalanan pariwisata yang bertujuan menuntut ilmu pengetahuan. dan perhatikanlah bagaimana akibat orang-orang yang mendustakan Rasulullah.” Syekh Jamaluddin AlQasimi dalam kitabnya Mahasin al-Ta'wil mengatakan : "Perintah untuk melakukan perjalanan pariwisata dan menyaksikan peninggalan kaum-kaum terdahulu adalah untuk mengambil pelajaran dari peninggalan tersebut.

Istana-istana yang tinggi, harta-harta yang terpendam, ranjang-ranjang tidur yang indah, beserta segala pernik-perniknya yang pada zaman dahulu merupakan sumber kebanggaan bagi manusia, kini telah lenyap dan tidak bernilai. Semua ini dimaksudkan Allah agar dijadikan pelajaran oleh umat-umat berikutnya." ${ }^{19}$ Salah satu cara Pemerintah Daerah mengundang tamu dari luar untuk memilih pendidikan dasar, menengah, atau bahkan perguruan tinggi adalah dengan membangun pusat pendidikan terpadu, memfokuskan kota pendidikan yang berstandar Nasional dan Internasional, jika ini terwujud secara tidak lansung dapat meningkatkan tarap kehidupan sosial masyarakat dan sikap intelektual dan perilaku positif dari individu masyarakat. Allah berfirman dalam Qs. Ali Imran (3) : 137

\footnotetext{
${ }^{19}$ Jamaluddin al-Qasimin, Mahasin al-Ta'wil, (Maktabah al-Halabi, Cairo, tanpa tahun), hal 36
} 


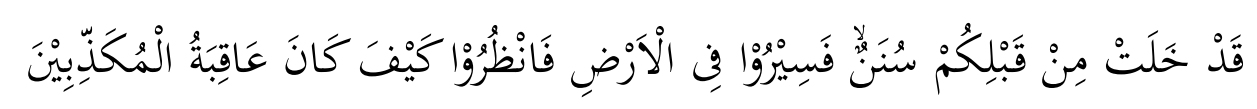

"Sungguh, telah berlalu sebelum kamu sunnah-sunnah (Allah), karena itu berjalanlah kamu ke (segenap penjuru) bumi dan perhatikanlah bagai-mana kesudahan orang yang mendustakan (rasul-rasul). (QS Ali Imran : 137)

\section{a. Tafsir Surat Al Imran Ayat 137}

\section{1) Tafsir Jalalain}

Ayat ini diturunkan berkenaan dengan kekalahan dalam perang Uhud (Sesungguhnya telah berlalu sebelum kamu sunah-sunah) artinya cara-cara Allah menghadapi orang-orang kafir yaitu menangguhkan kebinasaan mereka, lalu menghancurkan mereka secara tiba-tiba (maka berjalanlah kamu) hai orang-orang beriman (di muka bumi, dan lihatlah betapa akibat orang-orang yang mendustakan) para rasul, artinya kesudahan nasib mereka berupa kebinasaan. Maka janganlah kamu bersedih hati atas kemenangan mereka, karena Aku hanyalah menangguhkan kebinasaan mereka itu hingga pada saatnya nanti.

\section{2) Tafsir Ibnu Katsir Al Imran ayat 137}

Tafsir Surat Ali-'Imran: 137-143 Sesungguhnya telah berlalu sebelum kalian sunnah-sunnah Allah Karena itu. berjalanlah kalian di muka bumi dan perhatikanlah bagaimana akibat orang-orang yang mendustakan (rasul-rasul). (Al-Qur'an) ini adalah penerangan bagi seluruh manusia, dan petunjuk serta pelajaran bagi orang-orang yang bertakwa. Janganlah kalian bersikap lemah, dan jangan (pula) kalian bersedih hati, padahal kalianlah orang-orang yang paling tinggi (derajatnya), jika kalian orang-orang yang beriman. Jika kalian (pada Perang Uhud) mendapat luka, maka sesungguhnya kaum (kafir) itu pun (pada Perang Badar) mendapat luka yang serupa.

Dan masa (kejayaan dan kehancuran) itu Kami pergilirkan di antara manusia (agar mereka mendapat pelajaran); dan supaya Allah membedakan orang-orang yang beriman (dengan orang-orang kafir) dan supaya sebagian kalian dijadikan-Nya (gugur sebagai) syuhada. Dan Allah tidak menyukai orang-orang yang zalim, dan agar Allah membersihkan orang-orang yang beriman (dari dosa mereka) dan membinasakan orang- 
TAHKIM, Jurnal Peradaban dan Hukum Islam. Vol.3 No.l (Maret, 2020) | ISSN : 2597-7962

orang yang kafir. Apakah kalian mengira bahwa kalian akan masuk surga, padahal belum nyata bagi Allah orang-orang yang berjihad di antara kalian, dan belum nyata orang-orang yang sabar. Sesungguhnya kalian mengharapkan mati (syahid) sebelum kalian menghadapinya; (sekarang) sungguh kalian telah melihatnya dan kalian menyaksikannya.

Allah subhanahu wa ta'ala berfirman, ditujukan kepada hamba-hamba-Nya yang mukmin ketika mereka mengalami musibah dalam Perang Uhud hingga tujuh puluh orang di antara mereka gugur. Sesungguhnya telah berlalu sebelum kalian sunnah-sunnah Allah. (Ali Imran: 137) Yakni telah berlalu hal yang seperti ini di kalangan umat-umat sebelum kalian, yaitu mereka yang mengikuti nabi-nabi. Tetapi pada akhirnya akibat yang terpuji adalah bagi mereka, sedangkan kekalah-an dialami oleh orang-orang kafir. Karena itulah maka dalam firman selanjutnya disebutkan: Karena itu, berjalanlah kalian di muka bumi dan perhatikanlah bagaimana akibat orang-orang yang mendustakan (rasul-rasul). (Ali Imran: 137)

\section{Mendapatkan Ketenangan Jiwa dan Kebersihan Hati}

Tujuan lain dari dorongan Islam terhadap umatnya untuk melakukan perjalanan wisata, adalah untuk mendapatkan kesempatan bersenang-senang dengan cara yang sehat. Dalam berbagai riwayat Islam disebutkan bahwa mendapatkan kesenangan yang sehat dan bermanfaat bisa diraih dengan cara melakukan perjalanan dari kota ke kota atau dari negara ke negara lain. Menyaksikan berbagai ciptaan Tuhan yang indah, seperti gununggunung yang menjulang tinggi, sungai-sungai yang mengalir deras, mata air yang jernih, atau hutan-hutan yang hijau dan lautan yang penuh ombak, ini semua akan menimbulkan rasa senang dan kesegaran dalam jiwa manusia serta menambah kekuatan iman kepada sang khaliq. Selain itu, menemui kerabat dan sanak-saudara dengan tujuan untuk menjalin dan mempererat silaturahmi, merupakan tujuan lain dari pariwisata yang dianjurkan oleh Islam.

Dalam Hadis riwayat Bukhari dan Muslim, ${ }^{20}$ disebutkan bahwa silaturahmi akan memberikan kebaikan, membuka luas rezeki, membersihkan jiwa, dan mendapat

\footnotetext{
${ }^{20}$ Hadis tersebut berbunyi :

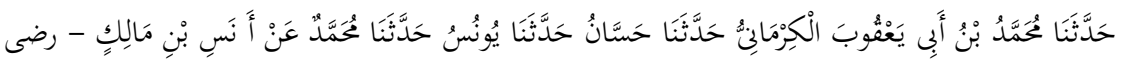


TAHKIM, Jurnal Peradaban dan Hukum Islam. Vol.3 No.l (Maret, 2020) | ISSN : 2597-7962

keberkahan hidup. Dalam hal ini Pemerintah Daerah dapat meningkatkan potensi wisata rohani, seperti kunjungan ke rumah Ibadah, Tadabbur Alam (wisata alam), tradisi keagamaan, dan lain sebagainya.

\section{SIMPULAN}

Setelah kita uraikan prinsip-prinsip Islam tentang pariwisata, maka dapat kita simpulkan sebagai berikut :

1. Berdasarkan ayat-ayat al-Quran dan Sunnah, pariwisata merupakan kegiatan mubah yang sangat di anjurkan, bahkan di perintahkan. Bukti sejarah dan perjalanan para nabi dan rasul di abadikan al-Quran dan sunnah, seperti berkunjung ke baitullah untuk menunaikan ibadah haji dan umrah, menunjukkan betapa pentingnya nilai sebuah perjalanan di muka bumi ini. Begitu juga anjuran Rasulullah melakukan wisata rohani ke tiga masjid bersejarah, yaitu ; Masjid Haram Makkah, Masjid Nabawi Madinah, dan Masjid al-Aqsa di Palestina.

2. Kegiatan bepergian dengan berbagai motivasi dewasa ini, menampilkan suatu rangkain kegiatan pariwisata yang berinplikasi pada berbagai sektor dan beragam aktivitas dalam kehidupan masyarakat. Hal ini berpengaruh baik secara positif maupun negatif terhadap berbagai permasalahan sosial, budaya, pendidikan, ekonomi, agama, kesehatan dan sebagainya. Prinsip Islam dalam hal ini berpegang pada skala prioritas dalam pekerjaan yaitu pekerjaan yang banyak dan lama manfaatnya, meninggalkan segala sesuatu yang kurang atau tidak bermanfaat sama sekali.

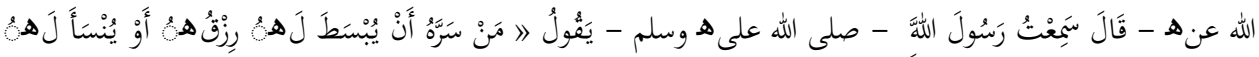

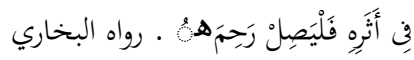

Artinya : "Barangsiapa yang ingin rezkinya berkembang dan diberikan kerberkahan dalam hidupnya, maka hendaklah ia menjalin hubungan silaturrahim”. Hadis ini terdapat dalam Saheh Bukhari kitab adab bab manyabsud lahu rizquhu bi shila al-rahim, no 5640, juz 5, hal 2232 dan Saheh Muslim kitab Adab bab shila al-Ramim wa tahrim qathi'iha, no 2557, juz 4, hal 1982. 
TAHKIM, Jurnal Peradaban dan Hukum Islam. Vol.3 No.l (Naret, 2020) | ISSN : 2597-7962

3. Pariwisata yang dikembangkan hendaknya benar-benar dikelola secara Islami dan berfungsi untuk kepentingan kesejahteraan lahiriah dan batiniah, khairat, ma'rufat tanpa maksiat dan mungkarat, dengan mengedepankan etika dan prinsip Islam.

\section{DAFTAR PUSTAKA}

Ibnu Katsir ad-Dimasyqi, Al-Imam Abul Fida Isma'il. (2002). Terjemah Tafsir Ibnu Katsir Juz. Bandung: Sinar Baru al-Gensindo.

Al-Mahally, Imam Jalaluddin dan As-suyutti, Imam Jalaluddin. (1990). Tafsir Jalalain Berikut Asbab An-nujulnya, Bandung,: Sinar Baru

Al-Anshari Al-Qurthubi, Abu Abdullah Muhammad. (1993). Al- Jami' Li Al-Ahkam alQuran. Beirut : Dar al-Kutub alllmiah.

al-Jauzi, I. Q.. (1973). I'lam al-Muwaqqi'in an Rabbi al-Alamin. Beirut : dar Jail, Baerut. al-Qasimin, J. (t.t) Mahasin al-Ta'wil. Cairo : Maktabah al-Halabi

Al-Raghib al-Alashfihani,(t.t) Mu'jam al-Quran Li Alfaz al-Quran. Beirut :Dar Fikr.

al-Utsaimin,Muhammad Bin Shaleh. (1422 H). al-Qawaid al-Fiqhiyah,. Iskandariah : dar al-Bashirah.

Bukhari, I. (1987). Jami' Shaheh Bukhari. Beirut : Dar Yamamah.

Departemen Agama Republik Indonesia. (1971). al-Quran al-Karim dan Terjemahannya. Saudi Arabia : Wakaf Khadim Haramain.

Dunn, Ross E. (2005), The Adventures of Ibn Battuta, University of California Press, ISBN 0-520-24385-4. First published in 1986.

Fuad Abdul Baqy, Muhammad. (1984). Mu’jam al-Mufahris Li- Alfaz al-Quran, Istanbul,. Turki : Maktabah Islamiyah.

Katsir, I.,(1986). Tafsir al-Quran al-Karim, . Beirut,cet 1,: Dar Maktabah al-Hilal.

Muhammad al-Sisi, Muhammad Khilal. (1994). al-Dhiya' al- Mubin fi Manahij alMuhadditsin. Cairo : Mathba'ah Amanah.

Muslim, I. (1985) Shaheh Muslim. Beirut : Dar Ihya Turats Arabi. 
TAHKIM, Jurnal Peradaban dan Hukum Islam. Vol.3 No.l (Maret, 2020) | ISSN : 2597-7962

Satori, Djam'an dan Komariah, Aan. (2009). Metodologi Penelitian Kualitatif. Bandung. Alfabeta.

Quthub, S. M. (1415 H) Fi Zhilal al-Quran. Cairo : Dar Syuruq.

Shalah, I. (t.t) Ulum al-Hadist, , Tahqiq Dr. Nuruddin 'Athar. Damaskus : Dar Fikr.

Syekh Muhammad Zarqa', Syekh Ahmad Bin. (1989). Syarah al-Qawaid al-Fiqhiyah, cet II. Damascus : dar al-Qalam.

Shihab, Q. (2002). Tafsir al-Mishbah. Jakarta : Lentera Hati. 
TAHKIM, Jurnal Peradaban dan Hukum Islam. Vol.3 No.l (Maret, 2020) | ISSN :2597-7962 
TAHKIM, Jurnal Peradaban dan Hukum Islam. Vol.3 No.l (Maret, 2020) | ISSN :2597-7962 